\title{
O USO DE FORMULÁRIOS COMO FERRAMENTA DA FUNÇÃO ORGANIZAÇÃO, SISTEMAS E MÉTODOS
}

\section{ARTIGO ORIGINAL}

FERREIRA, Nuryana Alves ${ }^{1}$

CAVALCANTE, Sueli Maria De Araujo ${ }^{2}$

FERREIRA, Nuryana Alves. CAVALCANTE, Sueli Maria De Araujo. 0 uso de formulários como ferramenta da função organização, sistemas e métodos. Revista Científica Multidisciplinar Núcleo do Conhecimento. Ano 05, Ed. 05, Vol. 09, pp. 133-146. Maio de 2020. ISSN: 2448-0959, Link de acesso: https://www.nucleodoconhecimento.com.br/administracao/uso-de$\underline{\text { formularios }}$

\section{RESUMO}

As ferramentas de Organização, Sistemas e Métodos são utilizadas nas organizações privadas e públicas a fim de promover a melhoria e eficiência dos processos. Neste contexto, este artigo tem como objetivo analisar a estrutura dos formulários utilizados da Pró-Reitoria de Planejamento e Administração - PROPLAD, da Universidade Federal do Ceará, tendo em vista a efetiva coleta de informações dos usuários. Apresenta como fundamentação teórica aspectos conceituais sobre a função de organização, sistemas e métodos, ressaltando os critérios de elaboração de formulários definidos por Roldan (2010). Trata-se de uma pesquisa do tipo descritiva,

${ }^{1}$ Graduanda em Administração na Universidade Federal do Ceará.

2 Professora da Faculdade de Economia, Administração, Atuária, Contabilidade e Secretariado Executivo, Universidade Federal do Ceará (UFC), vinculada ao Departamento de Administração e do Mestrado Profissional em Políticas Públicas e Gestão da Educação Superior (POLEDUC), da UFC. Doutora em Educação pela Universidade Federal do Ceará. 
com abordagem qualitativa e estudo de caso. Quanto aos procedimentos, classificase como pesquisa documental, fazendo uso de dados secundários, extraídos do portal da UFC. A análise dos formulários permitiu verificar que estes se encontram, em maioria, sob formato padronizado, com identificação da instituição e espaços suficientes para preenchimento dos campos. De forma semelhante, foram identificados aspectos que precisam de reavaliação, como por exemplo, o campo de assinatura sem detalhamento legível do nome do responsável do preenchimento. A análise permitiu mapear os pontos positivos e negativos na estrutura dos formulários, objetivando não comprometer o fluxo de comunicação e guarda das informações e evitar ruído nos processos.

Palavras-chave: Organização, sistemas e métodos, formulários, estrutura organizacional.

\section{INTRODUÇÃO}

A competitividade do mercado no contexto atual traz consigo a crescente necessidade de diferenciação das organizações. Nesse contexto de avanço, Cury (2012) fala sobre a importância da análise organizacional de uma organização como ferramenta que possibilita ao gestor uma visão ampla a fim de promover uma melhora contínua nos processos. O autor destaca ainda que essa análise, como parte da função OSM (Organização, Sistemas e Métodos), é um processo contínuo e dinâmico, mapeando e corrigindo erros de forma a otimizar a eficiência das organizações.

Dentre as ferramentas que dão apoio ao processo de melhoria dos processos e consequentemente, eficiência das empresas, destacam-se: organogramas, formulários e fluxogramas (JUNIOR, 2011).

Não apenas no setor privado, mas há uma crescente modernização da gestão pública, por meio de iniciativas das esferas federal, estadual e municipal. Tais iniciativas objetivam a melhoria da eficiência administrativa na prestação de serviços aos cidadãos (LIMA, 2015). O autor defende ainda que as crescentes melhorias nas capacidades de gestão pública decorrem da melhoria dos fluxos de trabalho, dos 
processos de tomada da decisão, de comunicação efetiva e de uma estrutura organizacional adequada.

A ferramenta formulário, parte da função de organizações e métodos, é utilizada para veicular informações de uma fonte emissora para um receptor, os quais devem organizados e padronizados de forma a transmitir a informação de forma ordenada e completa. Para que a informação seja conduzida de forma correta, o formulário precisa ser claro e objetivo, com campos definidos e com espaço suficiente para preenchimento. A Pró-Reitoria de Planejamento e Administração - PROPLAD da Universidade Federal do Ceará, instituição de ensino pública da esfera Federal, utiliza formulários como um componente organizacional, sendo estes indispensáveis no decorrer das atividades do corpo docente, discente e técnico-administrativos da instituição. A PROPLAD divulga em seu portal que o objetivo da utilização de formulários é permitir a uniformização dos processos da Pró-Reitoria, de forma a dispor as informações sistemática, racional e segmentadamente, proporcionando maior celeridade no andamento das atividades.

Neste contexto, este estudo tem como objetivo analisar a estrutura dos formulários utilizados pela PROPLAD - UFC tendo em vista a efetiva coleta de informações dos usuários.

\section{FUNÇÃO ORGANIZAÇÃO, SISTEMAS E MÉTODOS (OSM)}

Os conceitos de organização, sistemas e métodos são descritos a seguir individualmente, para depois serem apresentados como uma função da Administração, como um conceito conjunto. A definição de organização é trazida por Junior (2011) como sendo a ciência social que dispõe os elementos fundamentais necessários, produzindo um conjunto integrado e apto a apoiar o esforço colaborativo dos indivíduos que perseguem um objeto definido previamente. Já para Maximiano (2004), a organização é um atributo de qualquer conjunto estruturado ou ordenado segundo algum critério. $O$ processo de organizar aplica-se a qualquer coleção ou conjunto de recursos de forma que uma empresa organizada tem uma estrutura 
organizacional que identifica as responsabilidades, a autoridade e a comunicação entre as pessoas que nela trabalham.

Paz (2015) define sistema como um conjunto de ações que se complementam entre si, resultando em informações estruturadas para um fim determinado, sendo composta por: entrada, processamento e saída. A autora defende ainda que os sistemas permitem a agilidade das operações e contribuem para a redução de desperdício, podendo impactar positivamente nos lucros e na competitividade da organização.

O conceito de método dentro da função de Organizações Sistemas e Métodos é trazido por Paz (2015) como técnicas integradas que traçam um caminho lógico para a realização de tarefas, como forma sistematizada em busca de um objetivo.

Historicamente, o conceito da função Organizações e Métodos (O\&M) tem relação direta com a administração científica, dada por meio dos estudos de Frederick Taylor, Henry Fayol entre outros autores, permeada pela observação da necessidade de implantação de método para padronização de atividades, permitindo o melhor aproveitamento do recurso humano, reduzindo os custos e evitando desperdícios (ROLDAN, 2010). Após a reorganização do trabalho por meio de divisão de tarefas, padronização de métodos e desenho de cargos e atividades, trazida pela substituição de métodos empíricos pelos científicos, surge a Organização Racional do Trabalho (CHIAVENATO, 2003).

As organizações utilizaram-se da função de O\&M até o final dos anos 80 , quando ocorre a popularização dos recursos da informática, no qual as empresas precisaram se adequar e alinhar suas estratégias com os avanços da Tecnologia da Informação (OLIVEIRA, 2013). Surge então a função Organização, Sistemas e Métodos (OSM), que foi definida por Cury (2012) como sendo afunção da administração responsável pela modelagem da organização, tendo como responsabilidade atribuir melhorias aos setores, acompanhar e validar processos, contribuir com sugestões, observar e gerar conclusões utilizando-se de técnicas e procedimentos orientados ao resultado. 
Para Rocha (1998), OSM é definida como sendo a função mista de Organização e Planejamento, desenvolvendo-se na construção da estrutura de recursos e de operações de uma instituição, na determinação dos planos, principalmente na definição dos procedimentos, rotinas e métodos.

Assim, Llatas (2011) aponta algumas vantagens da OSM frente à O\&M, como uma função focada na criação de sistemas e métodos para obtenção de resultados, utilizando as ferramentas e técnicas da função como estratégias para atingir esses resultados com enfoque mercadológico, que pressupõem a melhoria da qualidade dos processos, redução de custos e satisfação do cliente.

Oliveira et al (2011) apontam como principais finalidades da OSM, os seguintes aspectos: i) padronização de procedimentos; ii) eliminação de atividades desnecessárias; iii) otimização de processos e recursos; iv) redução de custos; v) maximização de resultados; vi) racionalização na distribuição de tarefas; vii) elaboração de manuais e formulários; e viii) melhor distribuição do espaço através da otimização do layout.

A busca pela otimização dos processos operacionais trouxeram um novo cenário de atuação aos estudos de OSM, de forma a proporcionar otimizações de qualidade, agilidade e custos para a organização (MARQUES, 2012). O autor ainda sugere que essa evolução da OSM aliada à tecnologia da informação possibilita a automação de rotinas informatizadas e integradas, com recursos otimizados de operação, supervisão, controle e avaliação de processos, resultando em estruturas mais flexíveis e competitivas.

\section{FORMULÁRIO}

Um conceito de formulário é trazido por Araújo (2001, p. 96), o qual afirma que este "é um veículo que transporta informações de uma pessoa para outra, de uma unidade para outra, ou de uma empresa para outra". Na visão de Marques e Oda (2012), o formulário é um instrumento que atua como base para execução de processos organizacionais, através do armazenamento de informações. 
Já segundo Paz (2015), formulário é um documento pré-estruturado, possuindo campos para preenchimento de informações e dados, dispostos e organizados para um determinado fim. A autora fala ainda que formulários são utilizados de modo a facilitar o processo de comunicação, registro e controle de atividades de uma organização.

A importância da utilização de formulários é trazida por Roldan (2010) como fundamental para a sobrevivência de uma empresa, para coleta de dados e posterior acesso à estes. $O$ autor destaca também que formulários são utilizados para cumprir exigências legais, além de propiciar padronização interna, auxiliando no controle de processos e tarefas dentro dos fluxos organizacionais.

O autor destaca ainda que um formulário deverá ser criado quando possuir uma finalidade que justifique seu uso, podendo ser elemento chave para sanar deficiências no processo administrativo. A organização deve avaliar a extensão e a necessidade de determinados campos em seus formulários, utilizando de artifícios como fusão de formulários ou supressão de campos, a fim de aperfeiçoar o processo.

Uma classificação de formulários é trazida por Paz (2015), que categoriza os formulários em três grupos: Formulários Planos:campos impressos e preenchidos em papel; Formulários Contínuos: elaborados em papel, porém preenchidos em meio eletrônico; e por fim, formulários Eletrônicos: realizados em meio eletrônico, integralmente.

\subsection{CRITÉRIOS PARA CRIAÇÃO DE FORMULÁRIOS}

Para elaboração de um formulário, Roldan (2010) defende que é necessário o uso de questionários, no que inicialmente convêm serem utilizados como uma fase preliminar ao ciclo de fases ou etapas. O autor elenca essas questões em seu estudo teórico, apresentadas no Quadro 1: 
Quadro 1 - Critérios de elaboração e análise de formulários

\section{Questão}

Há padrões de medida uniformemente seguidos na seleção de papel para formulário?

As características de impressão diferem de um formulário para outro? Em outras palavras: há uniformidade na impressão dos formulários?

O objetivo está claramente colocado na parte superior? 0 título aparece claramente?

O tamanho é apropriado para seu manuseio, incluindo o seu preenchimento?

Os campos a serem preenchidos foram corretamente delimitados?

Os lançamentos são feitos de forma a economizar esforço?

Se o formulário é para ser preenchido a máquina, o espaçamento dado pela máquina é respeitado tanto na horizontal como na vertical?

A informação mais frequentemente necessitada, ou pela qual o formulário é preenchido, está localizada na parte superior?

As perguntas indicam, com evidência, a informação desejada?

O formulário é numerado?

O papel é de qualidade própria?

O papel não é mais caro (ou barato) do que deveria ser?

Fonte: Roldan (2010)

Por fim, o autor define a formulação de formulários como composta por etapas, a saber: (i) Levantamento e análise das necessidades, com o estudo do fluxo de trabalho e da viabilidade de aproveitamento dos formulários já existentes; (ii) Elaboração de novos formulários, considerando as variáveis de layout, tamanho e formato do papel, quantidade de vias e uso e finalidade do formulário; (iii) Teste dos 
formulários nas rotinas administrativas; e por fim, (iv) Recebimento, treinamento e controle de formulários.

\section{ORGANIZAÇÕES PÚBLICAS: ASPECTOS CONCEITUAIS}

O conceito de organização, no sentido econômico, é trazido por Marques e Oda (2012, p. 63) como "uma entidade composta por pessoas que buscam atingir um determinado objetivo, projetada como um conjunto sistêmico de atividades estruturadas e coordenadas que interagem com o ambiente externo". O autor classifica ainda as instituições em dois tipos de organização: formal, que é composta por normas, regras, organogramas com ênfase nas autoridades e responsabilidades, e ainda a organização informal, como uma interação que nasce espontaneamente da interação social, sem regras preestabelecidas, onde a liderança e autoridade surgem de forma natural sem sujeição a controles.

A complexidade, formalização, centralização e tamanho são, conforme Rossetto (1999), variáveis que definem o tipo de estrutura de uma organização. A autora define cada variável como: (i) Flexibilidade, relacionada à quantidade de níveis verticais e horizontais existentes na organização; (ii) Formalização como grau em que a organização adota regras e procedimentos para balizar comportamentos dos funcionários, (iii) Centralização como identificação da tomada de decisão e como esta se encontra na hierarquia da organização e (iv) Tamanho, englobando aspectos humanos e físicos. (ROSSETTO, 1999)

Conforme Oliveira (2011), uma estrutura organizacional adequada proporciona ganho no alcance dos objetivos da organização, delimitados no planejamento estratégico, mostra os níveis de autoridade e responsabilidade, promove a facilidade e qualidade nos processos decisórios e nos relatórios gerenciais, além de trazer melhorias na comunicação interna e externa da empresa.

O conceito de administração das organizações públicas é trazido por Bachtold (2008) e pode ser compreendida como a utilização de ferramentas tradicionais da Administração, tais como planejamento, organização, direção e controle, pelos entes 
que prestam serviços públicos, objetivando o bem comum. A administração das organizações públicas deve observar cinco princípios básicos, definidos no caput do artigo 37 da Constituição Federal de 1988, a saber: legalidade, moralidade, impessoalidade, publicidade e eficiência (BRASIL, 1988). Tais princípios, juntamente com o controle externo exercido sobre os entes federativos, permeiam um ambiente em que as ações do ente público devem ser pautadas sempre pela transparência.

Dentro das universidades públicas, percebe-se ainda a presença de estruturas burocráticas, principalmente nas atividades-meio, as que são essencialmente administrativas. Sobre a estrutura organizacional das universidades públicas, Leitão (1990) afirma que: Nesse tipo de organização, o principal meio de coordenação é a padronização das capacidades de seu pessoal operacional, que é componente fundamental da organização. Segundo seu modelo, a configuração burocrática na universidade se apoia mais na padronização das capacidades de seus professores e pesquisadores do que nos processos de trabalho, o que diferencia fortemente esse tipo de organização das organizações tipicamente burocráticas. São os procedimentos padronizados que permitem que cada profissional trabalhe com certa independência de seus colegas, fazendo-se a coordenação automaticamente através da padronização das capacidades adquiridas em sua formação acadêmica.

Apesar de processos padronizados trazerem vantagens no que tange à transparência, a tendência nessas estruturas burocráticas é a geração de baixos níveis de eficiência na movimentação dos fluxos internos, principalmente no tempo necessário para tomada de decisões sobre as demandas. Assim, como relação de causa consequência, a complexidade burocrática produz baixa eficiência na dinâmica dos fluxos, onde a excessiva quantidade de normas e de canais de informação gera um tempo longo para os fluxos decisórios (VIEIRA e VIEIRA, 2003).

Dentro da estrutura organizacional da Universidade Federal do Ceará está inserida a Pró-Reitoria de Planejamento e Administração, objetivando acompanhar dos processos de gestão, assim como garantir a segurança jurídica dos atos administrativos por meio de mecanismos de controle interno, mas tendo sempre como princípio fundamental o suporte adequado e tempestivo às atividades finalísticas da 
instituição. Como parte de uma instituição pública, a PROPLAD precisa manter os processos com base nos princípios da Administração Pública, principalmente no tocante à transparência e publicidade.

\section{METODOLOGIA}

Para o alcance dos objetivos propostos neste estudo foi desenvolvida uma pesquisa do tipo descritiva e com abordagem qualitativa, conforme classificação proposta por Gil (2008), a fim de analisar a estrutura dos formulários utilizados pela PROPLAD/UFC tendo em vista a adequação dos mesmos para a efetiva coleta de informações dos usuários, tendo como base os conceitos apresentados por Roldan (2010) como indispensáveis para elaboração de formulários.

Quanto aos procedimentos técnicos para a coleta de dados utilizou-se pesquisa documental tendo como base de dados o portal da UFC, sendo utilizado como objeto de estudo a estrutura organizacional e os formulários, instituídos pelo Provimento do Conselho Universitário da Universidade Federal do Ceará, sendo esta uma autarquia do poder público, vinculada ao Ministério da Educação (SILVA E GRIGOLO, 2002).

Este estudo utilizou uma amostra de 118 formulários da Pró-Reitoria de Planejamento e Administração da UFC, onde foram analisados tendo em vista os questionamentos definidos por Roldan (2010), adaptados para utilização neste estudo. Os dados coletados são classificados como secundários e foram catalogados, bem como, analisados por meio de inferências e interpretação, de forma objetiva e com base em regras explícitas.

Foram utilizados 13 critérios que devem ser observados na elaboração e análise de adequação de um formulário (Quadro 2).

Quadro 2 - Critérios de elaboração e análise de formulários, adaptado de Roldan (2010) para o estudo de formulários da PROPLAD

Item Questão 


\begin{tabular}{|c|c|}
\hline 1 & O formulário é editável eletronicamente? \\
\hline 2 & $\begin{array}{l}\text { Caso seja possível apenas o preenchimento manual, esse } \\
\text { preenchimento é feito de forma facilitada? }\end{array}$ \\
\hline 3 & É possível fazer a impressão do formulário em padrão A4? \\
\hline 4 & $\begin{array}{l}\text { O formulário é compacto suficiente de modo a racionar folhas e } \\
\text { impressão? }\end{array}$ \\
\hline 5 & O estilo do formulário é limpo? \\
\hline 6 & $\begin{array}{l}\text { É possível identificar o brasão da UFC e a identificação da Pró- } \\
\text { Reitoria de Planejamento e Administração? }\end{array}$ \\
\hline 7 & Existe uma padronização numérica presente no formulário? \\
\hline 8 & O campo data está apresentado? \\
\hline 9 & Os campos possuem tamanho suficiente para preenchimento? \\
\hline 10 & O formulário segue um layout ou modelo pré-estabelecido? \\
\hline 11 & $\begin{array}{l}\text { É possível a identificação suficiente do requerente ou responsável } \\
\text { pelo formulário? }\end{array}$ \\
\hline 12 & O formulário possui mais de uma página? \\
\hline 13 & Se sim, essas páginas estão numeradas? \\
\hline
\end{tabular}

Fonte: Elaborado pelas autoras (2020)

Foi identificado em cada formulário a resposta dos critérios, no binário 1 para a resposta sim e 0 para a resposta não, e calculado para cada item o somatório obtido sobre o total do universo dos dados, o qual será dado em porcentagem.

Os formulários utilizados neste estudo estão disponíveis para download no portal da UFC, especificamente no link da Pró-Reitoria de Planejamento e Administração. Assim, o servidor que necessite utilizar algum desses questionários pode baixar, imprimir e utilizá-los. 


\section{RESULTADOS}

A análise de 118 formulários disponíveis na página da Pró-Reitoria de Planejamento e Administração da UFC foi conduzida com base nos 13 critérios apresentados na metodologia, onde os resultados compilados são mostrados no Gráfico 1.

Gráfico 1 - Proporção de formulários que atendem aos critérios de elaboração e análise

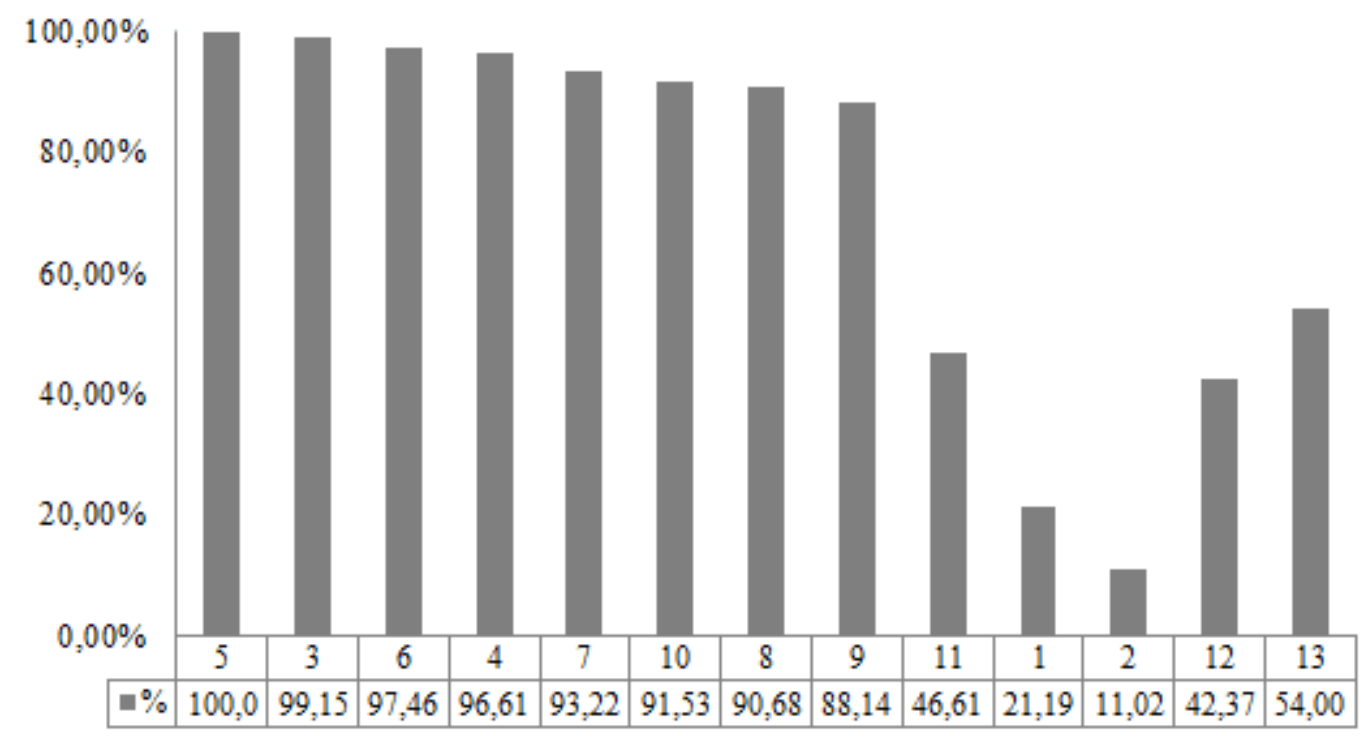

Fonte: dados da pesquisa (2020)

Pode-se inferir, a partir dos resultados apresentados, que 100\% dos formulários atendem ao critério: Limpo e de Fácil compreensão. Além disso, outros critérios apresentaram resultados positivos, como $99,15 \%$ dos formulários podem ser impressos em padrão A4 e que $96,61 \%$ são compactos suficientes de modo a evitar desperdício de papel. Ainda referente à forma, percebe-se que o brasão da UFC está presente em $97,46 \%$ dos formulários e que o código numérico de referência está presente em $93,22 \%$ destes. Um padrão pode ser percebido com um cabeçalho contendo o brasão da UFC e a identificação da Pró-Reitoria de Planejamento e Administração da UFC, além do título do formulário centralizado e o código numérico de referência ainda no cabeçalho, no lado direito superior. 
A Figura 1 apresenta um dos formulários analisados, utilizados pela PROPLAD.

Figura 1 - Exemplo de formulário adotado pela PROPLAD

\begin{tabular}{|c|c|c|c|c|c|c|}
\hline $\begin{array}{ll}\text { UFC } \\
\text { Led }\end{array}$ & \multicolumn{4}{|c|}{$\begin{array}{l}\text { Lista de verificação } \\
\text { RECONHECIMENTO DE DÍVIDA }\end{array}$} & \multicolumn{2}{|c|}{$\begin{array}{l}\text { Código: } \\
\text { PROPLAD097 }\end{array}$} \\
\hline \multicolumn{3}{|l|}{ Unidade Solicitante: } & \multicolumn{2}{|l|}{ № do Processo: } & \multicolumn{2}{|c|}{ Contato: } \\
\hline & $\mathrm{s}$ & $\mathrm{N}$ & EP & NA & & \\
\hline & Sim & Não & Em parte & Não se aplica & & \\
\hline & & & & & $\begin{array}{l}\text { S/N/ EP } \\
\text { OU NA }\end{array}$ & Folhas \\
\hline \multicolumn{5}{|c|}{$\begin{array}{l}\text { 1. Consta documento da unidade demandante solicitando o pagamento referente ao } \\
\text { reconhecimento de divida? }\end{array}$} & & \\
\hline \multicolumn{7}{|c|}{ 2. $\quad$ Estão especificados no processo: } \\
\hline \multicolumn{7}{|c|}{ 2.1. O objeto do reconhecimento da dívida? } \\
\hline \multicolumn{7}{|c|}{ 2.2. Dados do favorecido (nome, CNPJ)? } \\
\hline \multicolumn{7}{|c|}{ 2.3. Valor a pagar? } \\
\hline \multicolumn{7}{|c|}{$\begin{array}{l}\text { 3. Consta }(\mathrm{m}) \text { cópia da(s) nota(s) fical(is) referente(s) à dívida a ser reconhecida ou } \\
\text { documento equivalente? }\end{array}$} \\
\hline \multicolumn{7}{|c|}{$\begin{array}{l}\text { 3.1. Consta formulário PROPLAD063 - Termo de Atesto de Recebimento, devidamente } \\
\text { preenchido e assinado, se for o caso? }\end{array}$} \\
\hline \multicolumn{5}{|c|}{$\begin{array}{l}\text { 4. No caso de inexistência de contrato/instrumento equivalente, ou na ausência de } \\
\text { cobertura contratual (contrato vencido, aditivo assinado fora de época, produto ou serviço } \\
\text { não previsto no contrato, etc.), consta justificativa da execução da despesa, demonstrando } \\
\text { a necessidade e importância do serviço executado ou do produto adquirido (art. 59, PU e } \\
\text { art. } 60 \text {, PU, Lei no } 8666 / 93 \text { e Orientação Normativa/AGU no 04/2009)? }\end{array}$} & & \\
\hline \multicolumn{7}{|c|}{$\begin{array}{l}\text { 5. No caso da existência de contrato válido, constam no processo os seguintes } \\
\text { documentos (art. } 60 \text {, caput e art. } 63, \S 20,1 \text {, Lei } n=4320 / 64 \text { ): }\end{array}$} \\
\hline \multicolumn{7}{|c|}{ 5.1. Cópia do contrato? } \\
\hline \multicolumn{7}{|c|}{ 5.2. Se for o caso, cópia dos aditivos anteriores? } \\
\hline \multicolumn{7}{|c|}{ 5.3. Cópia da portaria de designação da equipe de fiscalização contratual? } \\
\hline \multirow{2}{*}{\multicolumn{5}{|c|}{$\begin{array}{l}\text { 5.4. Causa da inexistência do empenho, com as devidas justificativas pela ausência? } \\
\text { 6. Consta SICAF regular do fornecedor (IN SLTI/MPOG } n^{\circ} 02 / 2010 \text {, art. 3 e IN } \\
\text { SLTI/MPOG } n^{\circ} 02 / 2010 \text {, art. 14)? }\end{array}$}} & & \\
\hline & & & & & & \\
\hline
\end{tabular}

Observações complementares:

\begin{tabular}{|l|l|l|}
\hline Data & Verificado por: & Página de \\
\hline
\end{tabular}

Fonte: Universidade Federal do Ceará (2019) 
Nota-se ainda que, 91,53\% dos formulários seguem um layout ou padrão, conforme o formulário apresentado anteriormente, enquanto em 7 formulários são empregados fonte Times New Roman, saindo do padrão pré-estabelecido e identificado por comparação na análise. No tocante às margens, não foi percebida padronização, de forma que cada formulário tem dimensões próprias, deslocando visualmente o cabeçalho em relação comparativa. Há inclusive 2 (dois) formulários que as margens estão fora do limite de impressão, o que pode prejudicar o preenchimento de determinadas informações relevantes. Assim, apesar de serem índices favoráveis, com percentuais de resposta acima de $85 \%$, notamos que esses aspectos são de fácil rearranjo, possibilitando que estes documentos se apresentem ainda mais padronizados.

Roldan (2010) destaca a importância do campo intitulado "data" nos formulários, como uma forma de controle essencial para a organização. Em relação à presença deste campo, percebeu-se que há em $90,68 \%$ dos formulários, porém em 11 formulários não há campo de discriminação de data, o que pode ser avaliado como um potencial gerador de informações incompletas para a Pró-Reitoria de Planejamento e Administração da UFC.

A clareza da identificação do requerente ou responsável para elaboração ou recebimento do formulário é também um dos pontos de relevante importância na criação e avaliação de formulários (ROLDAN, 2010). Dessa forma, pode-se avaliar que em apenas $46,61 \%$ dos formulários fica clara a presença de campos de identificação, respondendo a questão do item 11. Contudo, em 46 dos 63 formulários que apresentam esse déficit, há um campo denominado "verificador por:", o que pode ser interpretado de forma relativa por quem está preenchendo o formulário, onde esta pessoa pode apenas assinar de forma descuidada, não deixando claro e legível seu nome naquele documento. Para este caso, propõe-se como solução a reformulação desses formulários, trocando por campos como "Nome em letra de forma; SIAPE/matrícula; Assinatura:" o que abrange toda a comunidade acadêmica. Ainda no tocante a campos, nota-se um aspecto positivo, onde $88,14 \%$ dos formulários apresentam campos de tamanho suficiente para preenchimento. 
Foi observado também que apenas $21,19 \%$ desses formulários em arquivos digitais são editáveis, o que pode representar uma demora no preenchimento, pois essa tarefa precisará ser feita manualmente. Além disso, 13 formulários, representando 11,02\% do totalapresentam campos já preenchidos e não possibilitam alterações nem mesmo para preenchimento manual, dessa forma, servem apenas como modelo para referência. Assim, quando necessária a utilização desses formulários específicos, o servidor precisa criar um novo documento, o que pode prejudicar o layout padronizado.

Nota-se também que há alguns formulários que apresentam mais de uma página. Para estes, foi avaliada a presença de campos indicativos de numeração de páginas. Observou-se que 23 formulários, equivalentes a $46 \%$ do total de formulários com mais de uma página, não apresenta indicativo de numeração. Tal fato pode desencadear eventuais problemas na organização do documento, principalmente no momento da impressão e do desarquivamento. Assim, propõe-se que sejam incluídos campos de preenchimento de página nestes formulários, indicando o número da página atual e o número total de páginas do documento.

A possibilidade de migração gradual de formulários impressos para formulários eletrônicos e a avaliação destes efeitos para a Pró-Reitoria de Planejamento e Administração da UFC não foi descartada e será discutido em estudo posterior.

\section{CONSIDERAÇÕES FINAIS}

Este trabalho teve como objetivo analisar as estruturas de métodos e organização da Pró-Reitoria de Planejamento e Administração - PROPLAD UFC, avaliada em formulários, de forma que foram identificados que a maioria dos destes atende a aos critérios apresentados.

Apesar de índices majoritariamente positivos, com adequação em mais de $85 \%$ dos formulários, observou-se que ainda há campos, como o de assinatura, que podem gerar ruídos no processo de comunicação. Ajustes em margens e no brasão da UFC foram sugeridas como forma de aperfeiçoar a padronização dos formulários. 
Acredita-se que o resultado deste estudo é um ponto de partida para estudos posteriores, na tentativa de otimizar os fluxos de operações envolvendo formulários, principalmente no tocante à adaptação aos recursos digitais, uma vez que organização inovação e eficiência são fundamentais na nova estruturação das universidades públicas.

\section{REFERÊNCIAS}

ARAUJO, Luis Cesar. Organização, sistemas e métodos e as modernas ferramentas de gestão organizacional: arquitetura organizacional, benchmarking, empowerment, gestão pela qualidade total, reengenharia. São Paulo: Atlas, 2001.

BÄCHTOLD, Ciro. Noções de Administração Pública. Curitiba: UFPR, 2008.

BRASIL. Constituição. Constituição da República Federativa do Brasil: texto constitucional promulgado em 5 de outubro de 1988. Disponível: em: <http://www.planalto.gov.br/ccivil_03-/constituicao/constituicaocompilado-.html>. Acessado em: 10 out. 2019.

CHIAVENATO, Idalberto. Introdução à teoria geral da administração: uma visão abrangente da moderna administração das organizações. 7. ed rev. e atual. - Rio de Janeiro: Elsevier, 2003.

CURY, Antonio. Organização e métodos: uma visão holística. São Paulo: Atlas S.A, 2012.

CURTO JUNIOR, Renato Mendes. Organização, Sistemas e Métodos. Rede E-Tec Brasil. Instituto Federal Paraná. Curitiba: 2011.

GIL, Antonio Carlos. Métodos e técnicas de pesquisa social. 6. Ed. São Paulo: Atlas, 2008 
LEITÃO, Sérgio Proença. Estrutura, cultura e desempenho organizacional na universidade. In: Rev. Adm. Pública. Rio de Janeiro, v. 24, n. 1, p. 31-43. nov. 1989/ jan. 1990.

LIMA, Jean Marcel Cunto; JACOBINI, Juliana Perez Ruggiro; ARAÚJO, Maria Arlete Duarte. Reestruturação organizacional: os principais desafios para o Ministério Público do Rio Grande do Norte. In: Rev. Adm. Pública. Rio de Janeiro, v. 49, n. 6, p. 1507-1530, nov./dez.2015

LLATAS, Maria Virgínia. OSM Organização, Sistemas e Métodos - Uma Visão Contemporânea. 1. Ed. São Paulo: Pearson, 2011.

MARQUES, Cícero; ODA, Cícero Marques Érico. Organização, Sistemas e Métodos. 1. ed. Curitiba: IESDE Brasil, 2012.

MAXIMIANO, Antonio Cesar Amaru. Teoria Geral da Administração - Da Revolução Urbana à Revolução Digital. 8. ed. São Paulo: Atlas, 2004

OLIVEIRA, Djalma de Pinho Rebouças de. Sistemas, organização e métodos: uma abordagem gerencial. 21a. Ed. São Paulo: Atlas, 2013.

OLIVEIRA, José Maria; BITTENCOURT, Jairo Alano; MOREIRA, Simone Aparecida; CHAGAS, Paulo César; PINHEIRO, Maria Adalgisa. A Representatividade das Técnicas de OSM para o Desenvolvimento das Organizações. 2011. VIII Simpósio de Excelência em Gestão e Tecnologia. Disponível em: www.aedb.br/seget/arquivos/artigos11/60814769.pdf. Acesso em: 13 set. 2019.

PAZ, Valdete. Organização, Sistemas e Métodos: Rede e-Tec Brasil. Universidade Federal de Mato Grosso. Cuiabá: 2015.

ROCHA, Luiz Oswaldo Leal. Organização e Métodos. São Paulo: Atlas, 1998.

ROLDAN, Lucas Baldisseroto. Caderno de Organização, Sistemas e Métodos. Santa Cruz do Sul: Faculdade Dom Alberto, 2010. 
ROSSETTO, Adriana Marques. Estrutura Organizacional Pública como um entrave à adoção de inovações em tecnologia de informações. ENANPAD. Anais, 1999

SILVA, Marise Borba de; GRIGOLO, Tânia Maris. Metodologia para iniciação científica à prática da pesquisa e da extensão II. Caderno Pedagógico. Florianópolis: Udesc, 2002

VIEIRA, Euripedes Falcão; VIEIRA, Marcelo Milano Falcão. Estrutura Organizacional e gestão do desempenho nas universidades brasileiras. . In: Rev. Adm. Pública. Rio de Janeiro, v. 37, n. 4, p. 899-920, jul./ago. 2003

UNIVERSIDADE FEDERAL DO CEARÁ. Pró-reitoria de Planejamento e Administração: Formulários e Checklists. Disponível em: <http://www.proplad.ufc.br/formularios-e-checklists/formularios-e-checklists/> Último acesso em: 12 jan. 2020.

Enviado: Janeiro, 2020.

Aprovado: Maio, 2020. 